\title{
WITHIN-FIELD SPATIAL DISTRIBUTION AND SAMPLING PLANS FOR LARVAE AND PUPAE OF DIAMONDBACK MOTH, PLUTELLA XYLOSTELLA L. (LEPIDOPTERA: PLUTELLIDAE) IN ETHIOPIAN HEAD CABBAGE FIELD
}

\author{
Gashawbeza Ayalew ${ }^{1}$, J. Baumgärtner ${ }^{2}$, C.K.P. O. Ogol ${ }^{3}$ and B. Löhr ${ }^{2}$ \\ ${ }^{1}$ Ethiopian Institute of Agricultural Research, PO Box 436, Nazareth, Ethiopia \\ E-mail: gashawbeza@yahoo.com \\ ${ }^{2}$ International Center of Insect Physiology. and Ecology, PO Box 30772, Nairobi, Kenya \\ ${ }^{3}$ Department of Zoology, Kenyatta University, PO Box 43844, Nairobi, Kenya
}

\begin{abstract}
Sampling statistics of three life stages of Diamondback moth (DBM), Plutella xylostella L., young larvae, mature larvae and pupae were calculated on head cabbage (Brassica oleracea L. var. capitata L.) in Ethiopia. Iwao's mean crowding regression was used to analyze spatial patterns and to derive sampling plans. The model accounted for $82 \%, 87 \%$ and $91 \%$ of the variation in mean crowding to mean relationship of young larvae, mature larvae and pupae of DBM, respectively. Distribution of all the three stages was contagious. Values of the intercept were not different from zero for all the three stages indicating that the basic components of the population are single individuals. Enumerative and action threshold-related sequential presence-absence sampling plans for population studies as well as decision making in integrated DBM control programs in cabbage field is developed.
\end{abstract}

\section{Key words/phrases: Action threshold, Brassica oleracea var. capitata, enumerative sampling, sequential sampling, spatial distribution}

\section{INTRODUCTION}

The Diamondback moth, Plutella xylostella (L.) (Lepidoptera: Plutellidae), is the most destructive insect of cruciferous plants throughout the world (Talekar and Shelton, 1993). In Ethiopia, reported yield loss on cabbage from the pest ranges between 36.1 and 91.2 per cent corresponding to 12 to 48.7 tons/ha, respectively (Gashawbeza Ayalew, 2006). Total crop failure is common in seasons of heavy infestation in central rift valley areas (Gashawbeza Ayalew and Ogol, 2006).

Diamondback Moth (DBM) eggs are laid on different parts of the plant including leaf, stem and petiole. The majority of eggs, however, are laid on the leaf in the proportion of 3:2 on the upper and lower leaf surface (Talekar and Shelton, 1993). Fecundity of between 293 and 320 eggs per female has been recorded on head cabbage in Ethiopia (Gashawbeza Ayalew et al., 2006a). Upon hatching neonate larvae start feeding on foliage. The first instar larvae mine in the spongy mesophyl tissue, whereas older larvae feed from lower leaf surface and usually consume all tissue except the epidermis of the upper surface, thus creating a window in the leaf. There are four larval instars. Total larval period ranges from 14 to 21 days (Abraham and Padmanaban, 1968). Upon completion of the larval stage, the mature caterpillars construct, on the host plant, a gauzy, loosely spun cocoon for pupation. The early yellowish-brown pupa progresses to brownish and attains a dark-brownish colour by the time of adult emergence. The pupal period varies from 4 to 15 days depending on temperature (Talekar and Shelton, 1993).

The ever-increasing difficulties associated with pesticide-based control of DBM led to the development of biological control projects within the framework of IPM programs (Carl, 1992; Talekar and Shelton, 1993). Efforts are being made by the Ethiopian Institute of Agricultural Research to develop a biological control based IPM program against the pest (Gashawbeza Ayalew and Ogol, 2006; Gashawbeza Ayalew et al., 2006b).

Knowledge on spatial distribution of an insect is an integral component in promotion of IPM (Bennett, 1993) and the basis for sampling plan design. Quantitatively describing spatial distribution allows an estimate of variance of insect count at different insect densities. Using estimates of variance, the optimal sample sizes to be used for analysis can be estimated. These are useful calculations because counting insects is tedious and time consuming, so it is of paramount importance to optimize the sampling strategy.

Sampling plan for DBM has not been available in Ethiopia. Hence, the objectives of the study were to describe the distribution of the larval and pupal stages of DBM on head cabbage and to develop 
sampling plans for density estimation in population dynamics studies and for decisionmaking in integrated pest management (IPM) programs.

\section{MATERIALS AND METHODS}

\section{Sampling procedures}

Data were obtained from population dynamics study conducted for three seasons between 2001 and 2002 at the Melkassa center of the Ethiopian Institute of Agricultural Research (EIAR). Field size was $30 \mathrm{~m} \times 18 \mathrm{~m}$ in the first season (March 2001) trial with spacing of $40 \mathrm{~cm}$ between plants and 60 $\mathrm{cm}$ between rows. In the second (March 2002) and third (November 2002) seasons, field sizes were 20 $\mathrm{m} \times 40 \mathrm{~m}$. The field for the first season experiment was divided in to 36 plots each having five rows of five-meter length. Sampling was made twice weekly at 3 to 4: days interval on one plant randomly taken from each row, resulting in a total of 180 plants per sampling occasion. In the second and third seasons, the field was divided into 12 plots each having 20 rows of $10 \mathrm{~m}$ length. A total of 240 plants were sampled per sampling occasion with sampling frequency similar to the first season experiment. The sample unit was a single plant. Accordingly, in each sampling occasion, all leaves of randomly selected plant were examined for the presence of yourig larvae, mature larvae and pupae, and the counts were recorded. Young larva refers to the first and second instars and mature larva refers to the third and fourth instars. Sample in this paper refers to all the units (plants) of a field at a given sampling date. The so collected data were used to analyze with-in field distribution patterns and to design sampling plans.

\section{Statistical analysis of the spatial distribution}

Davis (1994) reported that none of the numerous indices, regression models and distributions that have been used to evaluate dispersion are without some degree of criticism. Iwao's (1968) comprehensive mean crowding regression method was used. The method is based on Lloyd's (1967) mean crowding $(m c)$.

$$
m c=m+\frac{s^{2}}{m}-1
$$

where $m$ is the population mean, and $s^{2}$ is the variance. The mean and the mean crowding statistics were calculated for each sample. The mean crowding $m c$ was regressed on mean density $m$ according to the equation

$$
m c=\alpha+7 m \text {, }
$$

Estimates of the parameters $\alpha$ and $\beta$ were obtained by the least square method using PROC REG of the SAS statistical package (SAS Institute, 1999).

The proportion $(p)$ of infested plants was regressed on the mean density $(m)$ of mature larvae. Thereby, Bianchi et al. (1989) was followed and Nachman's (1984) model was used to express $p$ as a function of $m$

$$
p=1-e\left(-\alpha^{\prime} m^{\beta^{\prime}}\right) \text {. }
$$

The parameters $\alpha^{\prime}$ and $\beta^{\prime}$ were estimated via least square methods by means of the software specified above. This model enables translation of any action threshold $T_{m}$, expressed in numbers per plant, into an action threshold $T_{a}$, expressed as proportion of infested plants. Noteworthy, Nachman's (1984) model was derived from Taylor's (1961) power law relating sample variance to means, that would allow the interpretation of spatial distributions sirhilar to the mean crowding statistics used in this paper. Nevertheless, we exclusively used it here for translating $\mathrm{T}_{m}$ into $\mathrm{T}_{\mathrm{a}}$

\section{Enumerative sampling plan}

The reliability of estimates was defined by formal probabilistic statement (Karandinos, 1976), where $Z_{\alpha / 2}$ is the upper $\alpha / 2$ point of the cumulative standard normal distribution such that $P\left(Z>Z_{\alpha / 2}\right)=\alpha / 2$ and $\alpha$ is set at 0.05 for the $95 \%$ confidence interval (Hutchison, 1994) We used two reliability levels, $D_{m}=0.2$ and $D_{m}=0.3$.

On the basis of Iwao's (1968) regression model, Iwao and Kuno (1968) calculated the number $n$ of samples that corresponds to optimum sample size (oss) by

$$
n=\left(\frac{\frac{\frac{\alpha}{2}}{D_{m}}}{Z^{2}}\left[\frac{(\alpha+1)}{m}+\beta+1\right]\right.
$$

and also developed a sequential sampling procedure.

$$
T_{n}=\frac{(\alpha+1)}{c^{2}-\frac{(\beta-1)}{n}}
$$

where $T_{n}=$ cumulative total number of DBM, $n=$ required sample size, $c=$ desired reliability level 
defined as standard error to mean ratio of 0.20 and $0.30, \alpha$ and $\beta$ as defined in equation 2 .

\section{Presence-absence sampling plan}

For threshold-based control, a sequential presence-absence sampling plan with respect to the proportion of infested units is very cost-efficient (Bianchi et al., 1989). Originally proposed by Wilson et al. (1983), the method was applied for mature larvae.

$$
n=\left(Z_{\alpha / 2}\right)^{2}\left(p-T_{a}\right)^{-2} p(1-p)
$$

Where $n$ is the number of samples to be taken if the difference between the proportion $p$ of infested sampling units and the action threshold $T_{a}$ is equal to the confidence interval. The action threshold $T_{n}$ is derived from the density threshold $T_{m}$ by using equation 3 .

\section{RESULTS}

\section{With-in field distribution-}

A total of 85 samples were collected from the three seasons. Figure 1 shows the regression statistics for Iowa's mean crowding (equation 2) for each life stage. The model gave a significant linear relationship $(p<0.0001)$ of mean crowding to the mean density for the whole data set. It accounted for $82 \%, 87 \%$ and $91 \%$ of the variation in mean crowding to mean relationship of young larvae, mature larvae and pupae of DBM, respectively. The slopes of the regression line were significantly greater $(p<0.05)$ than unity for all the three stages of DBM. Values of the intercept were significantly different from 0 for all the three stages (Table 1).

Table 1. Statistics for Iwao's (1968) mean crowding to mean relationship relative to the distribution of three stages of Diamondback moth on head cabbage field in Ethiopia.

\begin{tabular}{llll}
\hline Life stages & $\mathrm{R}^{2}(\mathrm{p}$-value $)$ & $\begin{array}{l}\alpha \pm \mathrm{SE} \\
(\mathrm{p} \text {-value })\end{array}$ & $\begin{array}{l}\beta \pm \mathrm{SE} \\
(\mathrm{p} \text {-value })\end{array}$ \\
\hline Young larvae & $0.82(<0.0001)$ & $\begin{array}{l}0.67 \pm 0.15 \\
(<0.0001)\end{array}$ & $1.76 \pm 0.09(<0.0001)$ \\
Mature larvae & $0.87(<0.0001)$ & $\begin{array}{l}0.40 \pm 0.10 \\
(0.0002)\end{array}$ & $1.91 \pm 0.08(<0.0001)$ \\
Pupae & $0.91(<0.0001)$ & $\begin{array}{l}0.44 \pm 0.08 \\
(<0.0001)\end{array}$ & $1.72 \pm 0.05(<0.0001)$ \\
& & & \\
All stages & $0.92(<0.0001)$ & $0.08 \pm 0.21$ \\
Combined & & $(0.0002)$ & $1.59 \pm 0.05(<0.0001)$ \\
\hline
\end{tabular}

$\alpha=$ intercept of the regression equation.

$\beta=$ slope of the regression equation.
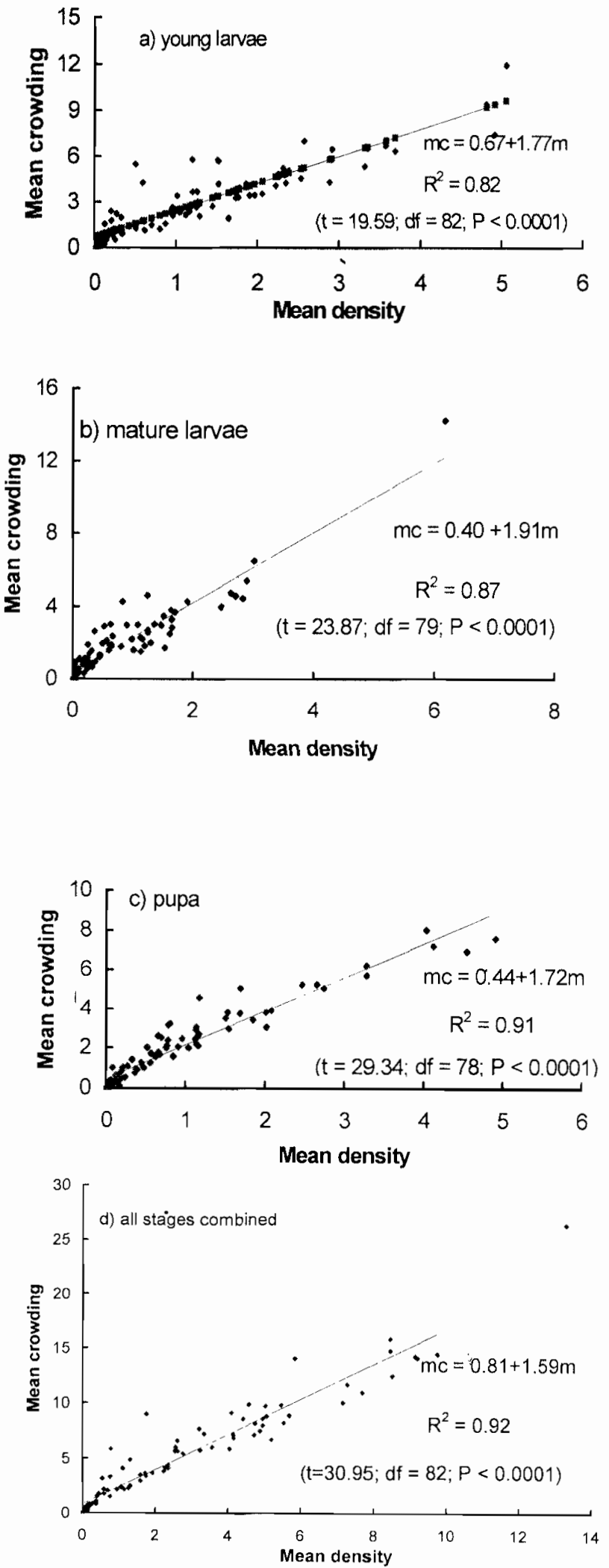

Fig. 1. The mean crowding to mean density relationship for with-in field distribution of various life stages of diamondback moth on cabbage $(\mathrm{mc}=$ mean crowding, $\mathrm{m}=$ mean density, $\mathrm{R}^{2}=$ coefficient of determination). 


\section{Enumerative sampling plan}

Figure 2 depicts the number of plants $n$ required to estimate mean clensity of the different stages of DBM. Accordingly the optimum sample size required to estimate low mean densities of the different stages of DBM goes as high as 600 and 270 for reliability levels of 0.2 and 0.3 . Between 250 and 300 plants; and 110 and 140 plants are required at mean density of five and above for reliability levels of 0.2 and 0.3 , respectively. Required sample size appeared to be higher for young larvae than the other stages. Figure 3 shows fixed precision-level sequential sampling. Starting with 20 plants, the number of individuals on the additional plants should be added to the ones obtained before and sampling stops whenever the stop line is reached or exceeded.
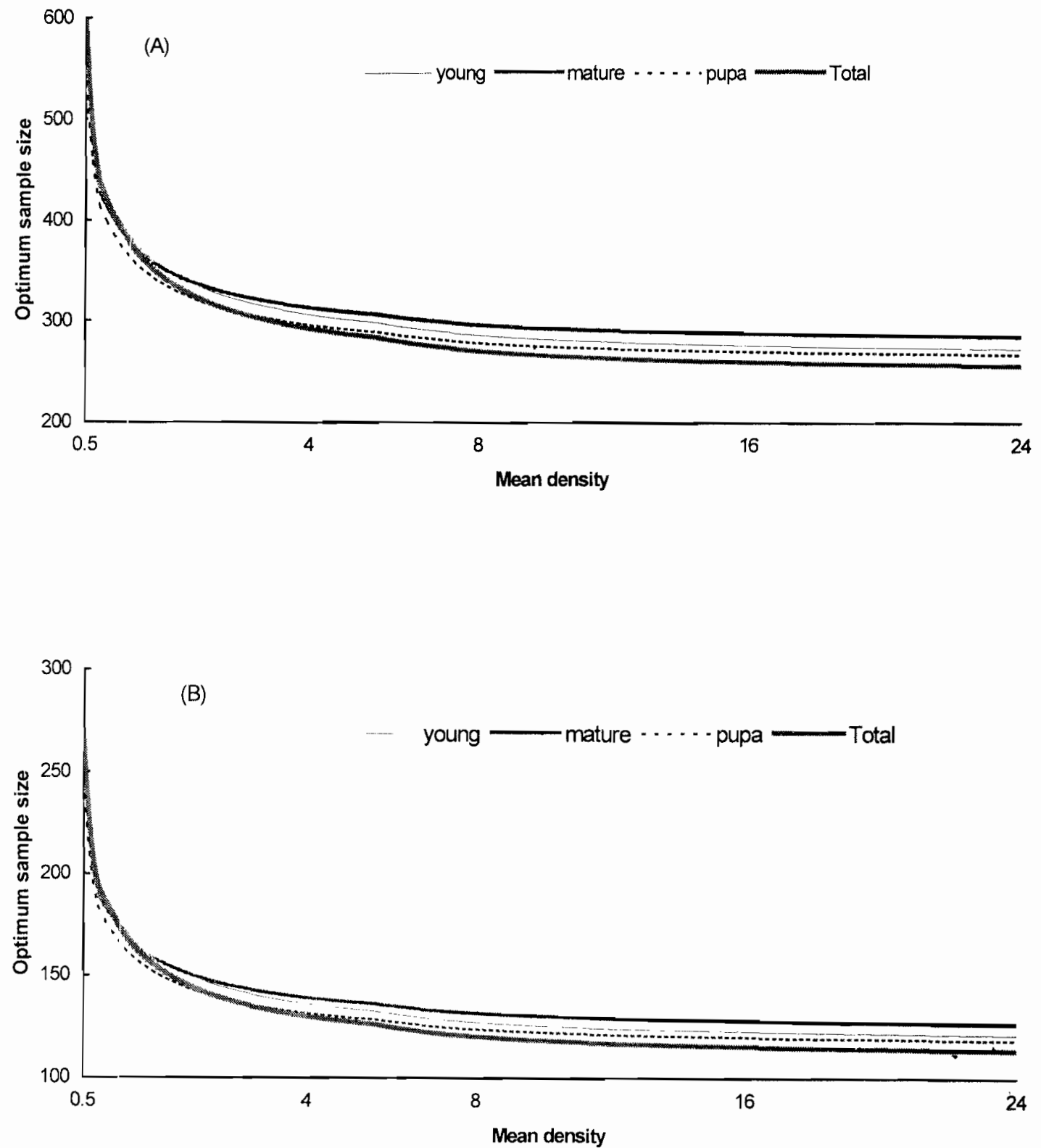

Fig. 2. Optimum sample size (OSS) required to estimate mean density of various life stages of diamondback moth for varying densities and reliability levels of $\mathrm{A}) \mathrm{Dm}=0.2$ and $\mathrm{B}) \mathrm{Dm}=0.3$ on head cabbage $(\mathrm{Dm}=$ mean density). 

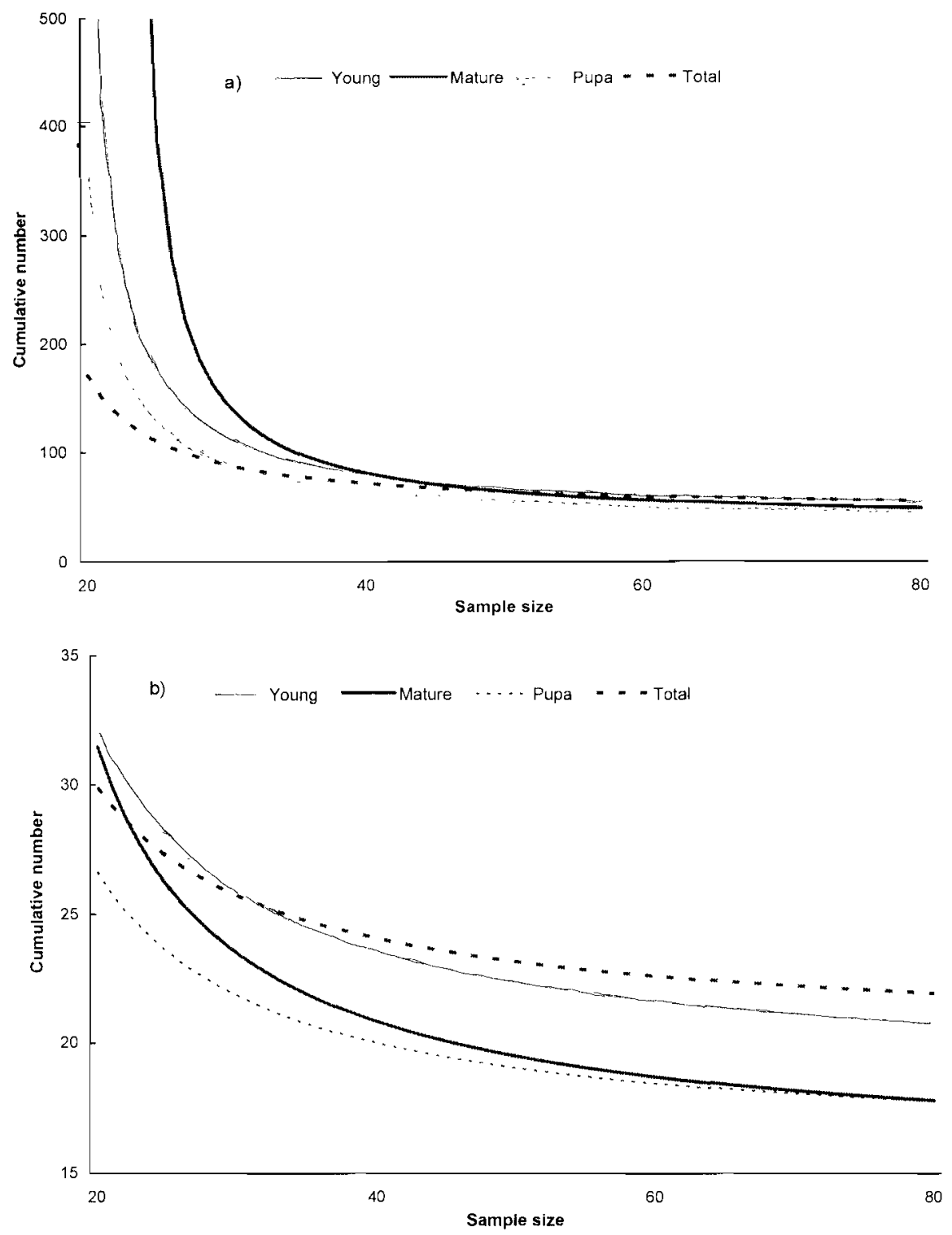

Fig. 3. Critical stop lines for sequential sampling plans to estimate mean densities of various stages of Diamondback moth at reliability levels of a) 0.2 and b) 0.3 .

On cabbage, no data on action threshold are available in Ethiopia. Chen and Su (1986) consider one larva per plant before the 10-leaf stage and two larvae per plant thereafter as the action threshold. This would correspond to $T_{a}$ of 0.37 and 0.62 infested sampling units respectively $\left(T_{d}\right.$ of equation $3)$. The relationship of infested sampling units and mean insect density (Nachman, 1984) for mature larvae on cabbage is shown in Fig. 4. Samples with mean density of 1 and 3 mature larvae per plant correspond to 37 and 78 per cent infested plants, respectively.

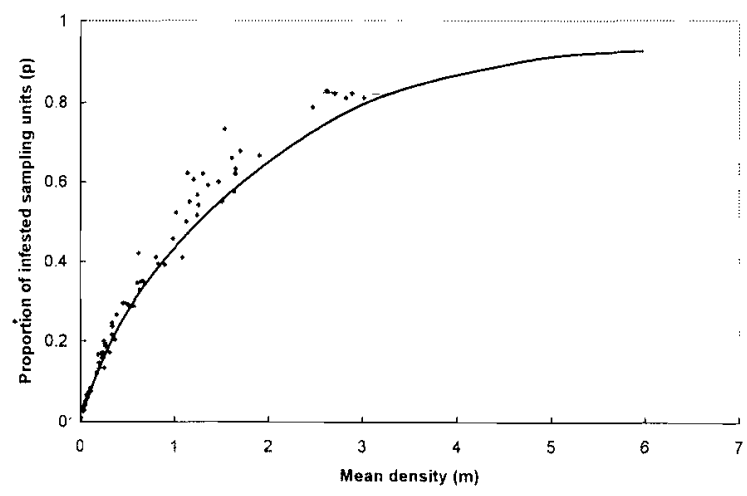

Fig. 4. The proportion of infested sampling units $(p)$ as a function of the mear insect density $(m)$ for mature DBM larvae on cabbage, $p=1-e\left(-0.460 \mathrm{~m}^{1.096}\right)$. 


\section{Presence-absence sampling plan}

Figure 5 shows the threshold related presenceabsence sampling plan that we designed for pest management purposes. This plan was developed for mature larvae on cabbage only because this stage is most easily identifiable by growers. The final sample size shouldn't exceed the oss of the enumerative sampling plan (Fig. 3), while the initial sample size is 20 plants for practical reasons (Bianchi et al., 1989). The number of infested plants with mature larvae is counted and as long as the proportion of infested plants falls within the two lines, new samples are taken. Once the proportion reaches or exceeds a line, sampling can be discontinued and a.decision can be made. The number of infested plants required to take a control decision before 10 leaf is smaller than thereafter. For example, a decision should be made when 25 infested plants are counted for a sample size of 50 before the 10-leaf stage. This corresponds to 37 infested plants for after 10-leaf stage (Fig. 5).
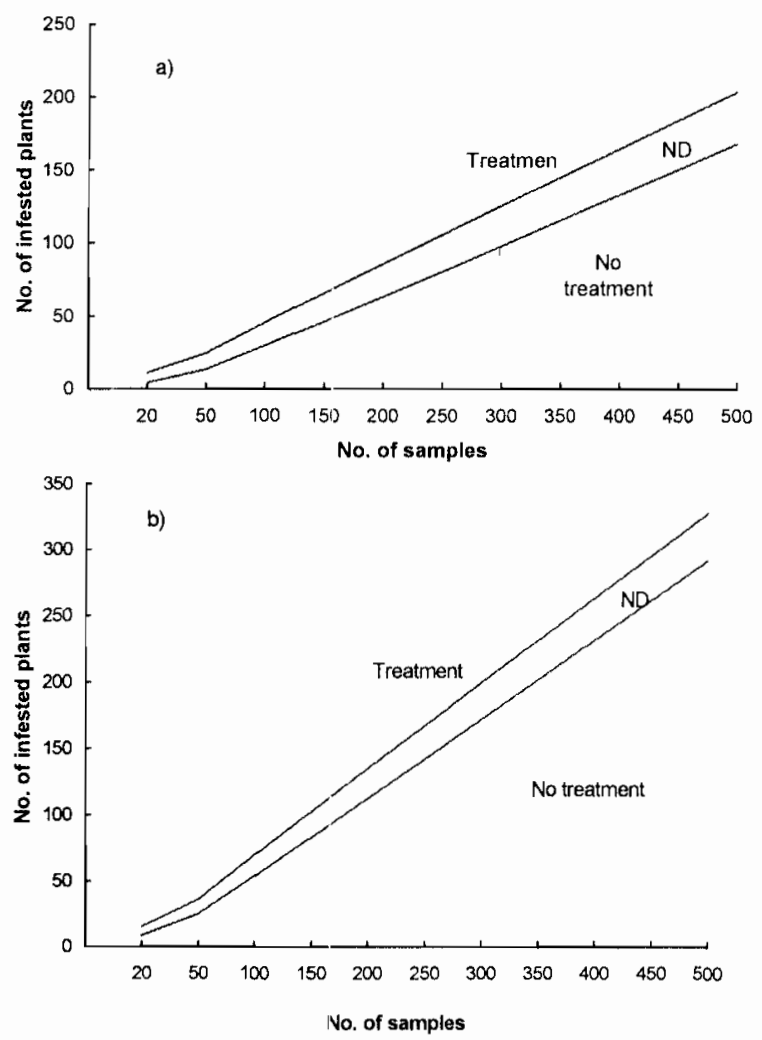

Fig. 5. Decision lines (a) before 10 leaf and (b) after 10 leaf stages of cabbage for sequential presence-absence sampling of mature DBM larvae relative to an action threshold. ND ständs for no decision.

\section{DISCUSSION}

The slopes of the regression models were significantly greater than unity for all the three stages indicating distribution is contagious (Iwao, 1968). Intercept values were not significantly different from zero for the whole data set indicating that, the basic components of the population are single individuals (Davis, 1994). Using one crown quadrant per plant, Harcourt (1961) proposed an optimum sample size ranging between 40 and 50 plants for a 10 per cent standard error for the larval and pupal stages of DBM. This figure is far below reports here at any level of insect density. This could be due to differences in the method used to develop the sampling plan and the condition of fields from which data were collected. Harcourt (1961) used coefficient of interplant variation for estimation of optimum sample size. On the other hand Chen and Su (1986) reported a similar result to ours. They reported a sample size ranging between 92 and 939 for lower mean density; and between 40 to 92 for higher mean density for reliability level of 0.2. A higher required sample size for young larvae than the other stages in density estimation is in agreement with reports of Harcourt (1961).

In African countries including Ethiopia, field sizes of brassica crops are small. In such fields, the OSS is tob high and the enumerative sampling plan is not applicable. However, the sequential sampling plans, applied in a nondestructive way, may allow obtaining reliable densities for population studies. For decision-making in integrated threshold-based pest management programs the application of the threshold-related presence-absence sampling plan, is therefore recommended. In general, the small sample size required makes this sampling plan more efficient for IPM relevant decisions than the enumerative sampling plan. The low number of sample units required confirms the cost-efficiency pointed out by Wilson and Room (1983) and Bianchi et al. (1989).

So far, a constant threshold has been used, but future research need to consider influences of factors such as yield levels, price of product and costs of control measures. Nachman's (1984) model could easily be adjusted to different threshold 
densities and action thresholds, and the thresholdrelated sequential binomial presence-absence sampling plan can be changed accordingly.

\section{ACKNOWLEDGMENTS}

We thank Markus Knapp (ICIPE, Nairobi) for helpful comments on the manuscript. Financial assistance was obtained from the German Ministry of Economic Cooperation and Development (BMZ) through the DBM bio-control project of the International Center of Insect Physiology and Ecology (ICIPE) and a scholarship to the senior author from the Deutscher Akademischer Austauschdienst (DAAD) through ICIPE.

\section{REFERENCES}

1. Abraham, E.V. and Padmanaban, M.D. (1968). Bionomics and. control of the diamondback moth, Plutella maculipennis Curt. Indian Joumal of Agricultural Science 38:513-519.

2. Bennett, A.L. (1993). Biology of Apion soleatum Wagner (Coleoptera: Apionidae) relative to cotton production in South Africa. African Entonology 1:35-47.

3. Bianchi, G., Baumgärtner, J., Delucchi, V., Rahalivavololona, N., Skillman, S. and Zahner, P.H. (1989). Sampling egg batches of Maliarpha separatella RAG. (Lep., Pyralidae) in Madagascar rice fields. Tropical Pest Management 35:420-424.

4. Carl, K. (1992). Potential for biological control in IPM for vegetable production in Africa. In: Regional Workshop on the Development and Application of Integrated Pest Management for Vegetable Production in Africa, pp. 203-212 (Traboulsi R., ed.). Dakar, Senegal.

5. Chen, C.N. and Su, W.Y. (1986). Ecology and control thresholds of the Diamondback Moth on crucifers in Taiwan. In: Proceedings of the First International Workshop on Diamondback Moth Management, pp. 415-421 (Talekar N.S., ed.) AVRDC, Taiwan.

6. Davis, P.M. (1994). Statistics for describing populations. In: Handbook of Sampling Methods for Arthropods in Agriculture, pp. 33-54, (Pedigo, P., and Buntin, G. D., eds). Boca Raton, Florida.

7. Gashawbeza Ayalew (2006). Comparison of yield loss on cabbage from diamondback moth, Plutella xylostella L. (Lepidoptera: Plutellidae) using two insecticides. Crop Protection 25:915-919.
8. Gashawbeza Ayalew and Ogol C.K.P.O. (2006). Occurrence of the diamondback moth (Plutella xylostella L.) and its parasitoids in Ethiopia: influence of geographical region and agronomic traits. Journal of Applied Entomology 130:343-348.

9. Gashawbeza Ayalew, Löhr B., Ogol, C.K.P.O. and Baümgärtner, J. (2006a). Suitability of cultivated and wild crucifers for the development of diamondback moth, Plutella xylostella (Lepidoptera: Plutellidae): Joumal of Entomology 3:82-88.

10. Gashawbeza Ayalew, Baumgärtner, J. Ogol, C.K.P.O. and Löhr B. (2006b). Analysis of population dynamics of diamondback moth, (Plutella xylostella (Lepidoptera: Plutellidae)) at two sites in central Ethiopia, with particular reference to parasitism Biocontrol Science and Technology 16:607-618.

11. Harcourt, D. G. (1961). Design of sampling plan for studies on population dynamics of the diamondback moth, Plutella maculipennis (Curt.) (Lepidoptera: Plutellidae). Can Entomol. 93:820831.

12. Hutchison, W.D. (1994). Sequential sampling to determine population density. In: Handbook of. Sampling Methods for Arthropods in Agriculture, pp. 208-243 (Pedigo, I'., and Buntin, G.D., eds). Boca Raton, Florida.

13. Iwao, S. (1968). A new regression method for analyzing the aggregation pattern of animal populations. Res. Popul. Ecol 10:1-20.

14. Iwao, S. and Kuno, E. (1968). Use of regression of mean crowding on mean density for estimating sample size and the transformation of data for the analysis of variance. Res. Pop. Ecol. 10:210214.

15. Karandinos, M. G. (1976). Optimum sample size and comments on some published formulae. Bull. Entomol. Soc. Am. 76:57-62.

16. Lloyd, M. (1967). Mean crowding. J. Anim. Ecol.36:130.

17. Nachman, G. (1984). Estimates of mean population density and spatial distribution of Tetranychus urticae (Acarina: Tetranychidae) and Phytoseiulus persimilis (Acarina, Phytoseiidae) based upon the proportion of empty sampling units. J. Appl. Ecol. 21:903-913.

18. SAS Institute. (1999). SAS/STAT. The SAS system for Windows, version 8.0. SAS Institute, Cary, NC.

19. Talekar, N.S. and Sheiton, A.M. (1993). Biology, ecology and management of the diamondback moth. Ann. Rev. Entomol. 38:275-301. 
20. Taylor, L.R. (1951). Aggregation, variance, and the mean. Nature 189:732-735.

21. Wilson, L.T., Pickel, C., Mount, R.C. and Zalom, F.G. (1983). Presence-absence sequential sampling for cabbage aphid and green -peach aphid
(Homoptera: Aphididae) on Brussels sprouts. I. Econ. Entomol. 76:476-479.

22. Wilson, L.T. and Room, P.M. (1983). Clumping patterns of fruit and arthropods in cotton with implications for binomial sampling. Environ. Entomol.12:50-54. 